\title{
Aspectos formativos do contrato na atualidade
}

\section{Erik Frederico Gramstrup ${ }^{1}$}

Andrea Cristina Zanetti ${ }^{2}$

RESUMO: O artigo visa à discussão de aspectos formativos do contrato envolvendo sua concepção como ato negocial e a forma como elemento de existência e requisito de validade, retirando conclusões que se afastam da visão tradicional. Foi seguido o método qualitativo com pesquisa bibliográfica. Chega-se ao corolário de que sistematização clássica da declaração negocial, do contrato e da forma substancial, se não deve ser de todo abandonada, deve pelo menos ser relativizada nas ocasiões discutidas.

PALAVRAS-CHAVE: Contrato. Consenso. Ato negocial. Comportamento concludente. Relações contratuais de fato. Forma substancial. Forma ad probationem. Boa-fé. Função Social. Conversão substancial. Conversão formal

\section{SUMÁRIO}

Introdução. 1. Contrato como negócio jurídico: revisão conceitual. 1.1.Visão tradicional do contrato e seus elementos. 1.2. Alargamento do termo consenso e contrato sem negócio. 1.2.1 Comportamento concludente e atos no seio de atividades. 1.2.2. Contrato sem negócio jurídico ou negócio de fato. 1.3.A relatividade da forma solene. 1.3.1 Princípio da boa fé objetiva. 1.3.2. Conversão do negócio jurídico nulo. Conclusão. Referências

\footnotetext{
${ }^{1}$ Doutor e Mestre em Direito pela PUC/SP. Juiz Federal. Professor de Direito Civil (PUC/SP). Professor da Faculdade Autônoma de Direito de São Paulo (FADISP), no curso de pós-graduação stricto sensu. Pontifícia Universidade Católica de São Paulo - PUC/SP, São Paulo - Brasil. E-mail: erikfg@uol.com.br

${ }^{2}$ Advogada. Doutora e Mestre em Direito pela PUC/SP. Professora de Direito Civil da graduação do Instituto de Direito Público de São Paulo (2018). Professora da disciplina de Processo Civil e Civil da pós-graduação da Escola Paulista de Direito (EPD). Professora convidada da pós-graduação da Escola Paulista de Magistratura (EPM). Instituto de Direito Público de São
Paulo
E-mail:

Brasil. andreazanetti78@gmail.com
} 


\section{Introdução}

O presente trabalho aborda certas dificuldades envolvendo a categorização do contrato como negócio jurídico e, também, a forma como elemento para existência, em face da forma como requisito de validade do ato. Esse esforço impôs que se repassasse a contribuição doutrinária das últimas décadas, abordando-se as teorias expansivas e restritivas do negócio jurídico; o impacto delas sobre o contrato enquanto declaração negocial; e as construções doutrinárias envolvendo o comportamento concludente e as relações contratuais de fato. Na sequência, aborda-se contribuição jurisprudencial (ecoando também lições da doutrina) sobre a relativização da forma; distingue-se a forma-existência da forma-validade e discute-se o impacto, na espécie, do princípio da boa-fé e do instituto da conversão substancial.

A relevância da discussão é indisputável. Revela a ambiguidade da própria noção de negócio jurídico e das disputas acerca da forma substancial mas, além do interesse puramente teórico, mostra porque a formação do contrato deve atender às necessidades da vida de relação ou, posto de outro modo, de sua função social, de modo a servir às necessidades de seus sujeitos e da vida comunitária.

\section{Contrato como negócio jurídico: revisão conceitual}

\subsection{Visão tradicional do contrato e seus elementos}

A doutrina tradicionalmente aponta o contrato como um exemplo de negócio jurídico, sendo que ambos os conceitos passam pela ideia de vontade. Ora apresenta o ato volitivo como a vontade em si (autonomia da vontade), que dá origem ao negócio jurídico, portanto, essencial a sua formação; ora o define como um preceito (ou mesmo "norma jurídica concreta") que tira a sua validade da norma abstrata imediatamente superior, dentro de uma concepção escalonada de normas jurídicas supra e infra-ordenadas, com que o atende, principalmente, ao caráter juridicamente vinculante de seus efeitos (auto-regramento da vontade) (AZEVEDO, 2010, p. 1/2). ${ }^{3}$

\footnotetext{
3 Há duas correntes doutrinárias que consideram a vontade como elemento do negócio jurídico conhecidas como teoria da vontade real ou subjetiva e teoria da declaração de vontade ou objetiva. A definição de negócio, segundo a tese subjetiva ou tese voluntarística (Willenstheorie), é ato jurídico que inclui a vontade do agente com o fim de criar ou desenvolver de uma relação jurídica. Os defensores da tese objetiva pautam-se na teoria de declaração da vontade (Erklärungstheorie), pela qual se assegura uma proteção mais efetiva da boa fé, da confiança de terceiro, em primeiro plano, já que é a declaração da vontade (e não a vontade em si mesma) que constitui elemento essencial do negócio jurídico, apresentando uma perspectiva objetiva da relação.
} 
Assim, o contrato como negócio jurídico apresenta em seus elementos essenciais, segundo José de Abreu Filho, o consentimento, a idoneidade do objeto, a forma e a causa (ABREU FILHO, 1995, p. 103). De forma semelhante Francesco Carnelutti trata como elementos intrínsecos gerais ao negócio jurídico a forma (prescrita ou não defesa em lei), a declaração de vontade (livre e consciente do agente) e o objeto (sua possibilidade, licitude, determinação ou determinabilidade) (CARNELUTTI, 1951, p. 236 e ss). Já nos elementos extrínsecos ao negócio jurídico aponta agente (capacidade, legitimidade), lugar e tempo. Ora, se não existisse tempo e lugar, sequer poderíamos considerá-lo como fato jurídico e, por sua vez, se inexiste agente de onde emana a vontade, não poderíamos classificá-lo como ato jurídico, gênero do qual o negócio jurídico é espécie ${ }^{4}$. Portanto, quanto se trata desses elementos, estamos no plano da existência do contrato. Sem tais elementos, o contrato sequer existe, razão pela qual os estamos pressupondo para tratar do contrato no plano da validade e eficácia. A forma e o objeto, enquanto tais, também pertencem ao plano da existência, pois sem elas não haveria negócio algum ou, pelo menos, tratar-se-ia de outra espécie de negócio. Para avançar em direção aos planos da validade e da eficácia, o foco deve voltar-se para certos qualificativos (como a licitude) e não para a forma e o objeto em si mesmos. Diante das qualificações presentes no artigo 104 do CC/2002, que requer para validade do negócio jurídico - e logo, do contrato - agente capaz; objeto lícito, possível, determinado ou determinável; forma prescrita ou não defesa em lei, avançamos pelos planos da validade e da eficácia.

Assim, considerando a definição acima, a falta ou a inobservância das qualidades exigidas quanto aos elementos essenciais do negócio levaria a sua nulidade ou anulabilidade.

Por exemplo, se não houver manifestação de vontade livre, de agente capaz, o negócio será nulo (como no caso de coação física, art. 151 a 155 e art. 166, IV e V do CC/2002 e celebrado por absolutamente incapaz - art. 166, I do CC/2002) ou anulável (diante dos vícios de consentimento de estado de perigo e lesão, respectivamente, arts. 156 e 157 do CC/2002). De forma semelhante, o contrato que não observar requisito legal - como a doação ou venda e compra de imóvel superior a trinta salários mínimos desacompanhado de escritura pública - também será invalidado. ${ }^{5}$ Não obstante a fixação dessas consequências, o que se tem notado na atualidade, é uma relativização interpretativa tanto para a definição clássica de contrato, que considera o

\footnotetext{
$4 \quad$ O negócio jurídico é tradicionalmente classificado como um tipo de fato humano ou ato jurídico lato sensu (manifestação de vontade humana que provoca efeitos jurídicos). Vale assinalar que o negócio jurídico é ato jurídico lato sensu voluntário (Isso porque também temos nessa divisão atos cujos efeitos jurídicos são involuntários - ato ilícito). (Cf. LOTUFO, 2004, p. 266/267)

5 Exemplo: Art. 108 do CC: Não dispondo a lei em contrário, a escritura pública é essencial à validade dos negócios jurídicos que visem à constituição, transferência, modificação ou renúncia de direitos reais sobre imóveis de valor superior a trinta vezes o maior salário mínimo vigente no País.
} 
consenso de duas ou mais vontades para constituir, regular ou extinguir relações jurídicas patrimoniais (BIANCA, 1987, p. 2); quanto na decretação da invalidade pela inobservância de algumas das qualidades exigíveis do contrato enquanto negócio. No que tange ao conceito de contrato, esse é alvo de novos estudos e dúvidas que surgem com as mudanças e ajustes constantes da sociedade atual, pós-moderna, impulsionada por inovações tecnológicas. ${ }^{6}$ Neste sentido, com o surgimento e disseminação do contrato eletrônico emergem questões relativas à real necessidade de manifestação da vontade. Afinal, muitas compras são realizadas virtualmente a partir de um simples click, o que implica em um ato, mas não na declaração de uma vontade. Além disso, crianças podem entrar em sites de jogos, realizar o download do aplicativo pago e utilizá-lo diretamente e, mesmo entre empresas, já existem softwares que permitem a compra e venda de mercadoria pré-programada, inclusive com emissão de nota fiscal eletrônica, sem a necessidade da intervenção humana .Ainda, quanto à forma, outro elemento essencial do contrato, vale mencionar que o próprio legislador criou instrumentos que minimizam consequências de nulidade ou anulabilidade, cioso da importância do contrato no contexto econômico e social atual, permitindo seu aproveitamento com base nos princípios da boa fé objetiva (arts. 113 e 422 do CC/2002) e conservação do negócio jurídico; além de situações que incluem a boa fé de terceiro (ex. art. 167, § $2^{\circ} \mathrm{CC} / 2002$ ); e a possibilidade de conversão do negócio jurídico nulo (art. $170 \mathrm{CC} / 2202)$.

\subsection{Alargamento do termo consenso e contrato sem negócio}

O contrato reflete a relação social de uma época. No século XIX, as relações comerciais eram marcadas por transações comerciais instantâneas, contratos de compra e venda marcados pela pessoalidade das relações e por estruturas simples na fabricação, fornecimento e forma de aquisição de bens materiais, pautados no indivíduo e em sua vontade.

Essa estrutura modificou-se ao longo de dois séculos e, na atualidade, diante de contratos de massa, adesão e longa duração; pautados em oferta pública (impessoalidade); cuja produção em série de bens e utilização de serviços ganha complexidade mundial, realizados em ambientes virtuais e extraterritoriais a partir de atos que não necessariamente requerem a expressão de uma vontade singular, duas correntes doutrinárias podem ser identificas na análise das mudanças do contrato e seus reflexos para o negócio jurídico: a) teoria expansionista do negócio jurídico, que amplia o sentido de vontade ou declaração de vontade para

\footnotetext{
6 Assim, assinala Francisco Amaral: A sociedade contemporânea, pós-moderna ou pós-industrial, é uma sociedade 'pluralista, complexa, marcada pela revolução técnica, pela mundialização da economia, pela massificação dos meios de comunicação'. Dado o notável desenvolvimento científico e tecnológico das últimas décadas é reconhecidamente a sociedade do conhecimento e da informação. (AMARAL, 2006. p.45) Neste mesmo sentido Miguel Reale: o equilíbrio social ... surge como equilibrio relativo e instável: sobretudo nas épocas marcadas por incessantes mutações tecnológicas, ou por bruscas e inesperadas alterações no quando dos valores psicológicos e éticos. (REALE, 2014, p.100).
} 
incluir atos e atividades que visam à conclusão do contrato; e b) teoria reducionista do negócio jurídico, que mantém apenas a declaração de vontade como elemento do negócio e, por isso, admite contratos sem negócio.

\subsubsection{Comportamento concludente e atos no seio de atividades}

A vontade em si, manifestada a partir de uma declaração em consenso dos contratantes não deve ser tomada de forma restrita. Autores contemporâneos, atentos `à evolução social, têm ampliado o sentido de vontade e consenso.

Emílio Betti diferencia declaração e comportamento concludente para concluir que o contrato poderá ser reconhecido a partir de uma declaração ( ato cujo evento se concretiza no outro a partir da vontade do destinatário ) ou de um comportamento, este último sem valor de declaração. O autor faz a distinção alertando para o erro de recorrer à ideia da "vontade" em seu estado puro, a fim de justificar a existência daqueles negócios originários do simples comportamento concludente e, também, para explicar que o negócio consistente no comportamento dirigido a destinatário indeterminado não poderia ser considerado como uma “vontade hipotética” (BETTI, 2008, p. 194). Logo, esses comportamentos são expressão objetiva da própria autonomia no seu sentido social, desvinculadas da exigência de uma consciente "manifestação", que possibilita o vínculo e regulamentação entre os particulares, surtindo os mesmos efeitos a vontade declarada, sendo reconhecidos pela meio social como atos de tomada de posição de um sujeito a respeito de interesse alheio, afetando sua esfera e, consequentemente a esfera do outro interessado. São aferíveis objetivamente a partir do exame do conjunto das circunstâncias, sendo classificados como comportamentos qualificados e concludentes do negócio jurídico (BETTI, 2008, p. 206). Também Túlio Ascarelli, ao tratar da atividade comercial (empresarial, administrativa e laborativa), assevera que ela (attività) não é um simples ato, mas um conjunto de atos coordenados e orientados a uma finalidade comum (ASCARELLI, 1962, p. 147) ${ }^{7}$. Esse conjunto de atos, como esclarece Giuseppe Auletta, pode adquirir um valor tão relevante na ordem jurídica que se estabeleça uma normativa exclusiva ou distinta daquela existente para os atos isoladamente considerados. Assim, foi elaborado em época recente o conceito de atividade, associando-se àquele conjunto de atos aos quais o ornamento atribui relevância jurídica também em seu complexo(...)(AULETTA, 1958, p. 982): Neste contexto objetivo, a atividade - que aqui é apresentada como próprio conceito de contrato deve ser vista como uma coordenação de atos praticados por centros de interesse (e não a vontade em si) que

\footnotetext{
7 Tradução do trecho - Attività non significa atto, ma una serie di atti tra loro coordinabili in relazione ad una comune finalità e il termine «atto», anzichè nella sua portata giuridica tecnica, deve essere a questo riguardo inteso, almeno per le persone fisiche, como equivalente "ad affare" a sua volta poi resultante a uno o più atti giuridici, chè, per le persona fisiche, é una pluralità di" affari" e non puramente di "atti".
} 
concluem uma relação jurídica. Isso ocorre naturalmente, sem que as partes manifestem uma vontade de coordenação dos atos que praticam.

Ainda nessa mesma linha, encontramos autores que se questionam, inclusive, sobre a necessidade de consenso, em seu sentido tradicional de acordo de vontades. Isso se dá no âmbito dos contratos eletrônicos, em especial a compra e venda nas relações de consumo, no âmbito das "redes" e da "internet", onde observamos: a) uma substituição do espaço geográfico pelo abstrato e virtual, e b) da palavra ou diálogo pela imagem e mera precificação (IRTI, 1998, p. 347-364). Ainda, para Natalino Irti $^{8}$, esse movimento implica na compreensão de que o acordo (consenso) da vontade acaba sendo substituído por atos unilaterais (expor e escolher), dissociando-se do acordo (IRTI, 1958, p. 52). Assim, na atualidade, em especial nos contratos de massa, o declínio do acordo - decorrentes da crise da palavra e do diálogo - dissolve o contrato como "acordo ou consenso de duas ou mais vontades". Para o autor o contrato nesta concepção se limitaria a combinação de dois atos unilaterais: exposição (exibição) e preferência, requerendo somente a possibilidade de ser rastreado o autor do ato e a capacidade natural de entendimento e de manifestação de vontade. Na doutrina portuguesa, Antônio Menezes Cordeiro, ao afastar o comportamento concludente da exteriorização da vontade, identificando como comportamento rotineiro ou padrão que implica em forma de aceitação, esclarece: "ficcioso pretender, neles, ver declarações, ainda que encapotadas, de vontade. [...] o verdadeiro comportamento concludente não exprime vontade: apenas uma rotina ou um comportamento-padrão" (CORDEIRO, 2005, p. 596/597). Para o autor a exigência de exteriorização da vontade não pode ser exigida nos negócios de massa (teria ela pouco valor relativo). As pessoas poderiam pautar-se, nesses casos, nas condutas habituais, atuações instintivas e outros, sem que o Direito as obrigue a uma "permanente vigilância jurídica". Portanto, o comportamento tende à formação do contrato e vincula como se fosse uma declaração volitiva, mas com essa não se confunde .

Como contraponto, Paulo Cardoso Correia da Mota Pinto, trata também dos comportamentos concludentes como forma de declaração capaz de dar origem a obrigações contratuais. Para tanto analisa o

\footnotetext{
$8 \quad$ O intercâmbio entre coisa e dinheiro, a compra e venda resultante da medieval in 'rerum commutatio' não necessita nem da palavra, nem do diálogo, nem do acordo: mas apenas da congruência exterior, que está em expor as coisas e a escolha de uma delas. Essas decisões são absolutamente unilaterais, e encontram-se, não mais na mediação unificadora do diálogo, mas a incidência sobre a própria coisa. A identidade da coisa, exposta por um e preferida por outro, é a única medida de consonância entre as partes. A troca desenvolve-se sem diálogo, ou seja, sem a plenitude e intensidade da linguagem do acordo. Do trecho: "Lo scambio tra cosa e danaro, la compravendita risolta medioevalmente in rerum commutatio, non ha bisogno né di parole, né di dialogo, né di accordo: ma soltanto di quella esteriore congruenza, che sta nell'esporre le cose e nello scegliere una di esse. Le quali decisioni sono affatto unilaterali, e si ritrovano, non già per l'unitiva mediazione del dialogo, ma per l'incidenza sulla medesima cosa. L'identità della cosa, esposta dall'una e preferita dall'altra, è l'unica misura di consonanza tra le parti. Lo scambio si svolge senza dialogo, cioè senza la pienezza e l'intensità dell'accordo linguistico". (IRTI, 1998, p. 353/354)
} 
que caracteriza a concludência e afirma, de forma diversa de Menezes Cordeiro, que ela é elemento objetivo da declaração tácita negocial, mas não pode ser traduzida como volitiva (MOTA PINTO, 1995, p. 746/747). Para chegar a essa afirmação, entendemos que Paulo Cardoso Correia da Mota Pinto teve que adaptar o sentido de negócio jurídico, de uma forma diversa da visão tradicional, alargando seu conceito para que pudesse abranger os comportamentos concludentes. A declaração tácita não provém de uma deliberada expressão da vontade, mas de um significado declarativo, que se pode constituir a partir da ilação ou 'juízo de concludência'. Afinal o comportamento concludente advém de um nexo de conclusão extraído da interpretação de uma conduta e das respectivas circunstâncias, dada a ausência de linguagem verbal ou escrita (MOTA PINTO, 1995, p. 748 e 753). A primeira conclusão que se retira dessas teorias é o esforço doutrinário para cobrir aspectos novos das relações sociais que advêm com os contratos de massa, em larga escala, em que a oferta é feita sem visar um sujeito determinado. A segunda impressão é a necessidade de revisar o conceito de contrato, que não implica no seu desfazimento, mas em interpretar seus elementos tradicionais para receber novos valores e comportamentos sociais, acompanhando a evolução da sociedade.

Por isso mesmo, para a formação do contrato deve-se considerar a existência de uma declaração de vontade por meio de signos verbais ou escritos e, em sua ausência, também os aspectos circunstanciais que levam a formação do contrato a partir da análise de um conjunto de atos que resulte em um comportamento concludente, capaz de estabelecer o vínculo contratual com as consequências dele decorrentes.

Essa é uma realidade que se nota no Brasil. Foi exatamente pautando-se na ideia de comportamento concludente que a $1^{\mathrm{a}}$ Câmara de Direito Privado do Tribunal de São Paulo, na apelação ${ }^{\circ}$ 1001390-67.2016.8.26.0344, tendo como relator Des. Francisco Loureiro, j. 17/01/2017, reconheceu a legitimidade passiva de empresa de construção imobiliária que, mesmo não tendo figurado expressamente no contrato, colaborou comprovadamente de forma indireta para o empreendimento imobiliário que, diante do atraso das obras motivou ação de resolução visando ao desfazimento do contrato de compra e venda de imóvel c/c com alienação fiduciária. ${ }^{9}$ Portanto, o que nos parece relevante não é aceitar ou não o comportamento

\footnotetext{
9 Irrelevante, pois, a argumentação de que foi a requerida URBPLAN DESENVOLVIMENTO URBANO S/A que deu causa com exclusividade ao atraso na conclusão da obra. A propósito, a legitimidade da última ré mencionada também é evidente, ainda que não tenha figurado expressamente no contrato firmado com os autores. Afinal, os documentos de fls. 29 e 54/58 demonstram que a URBPLAN colaborou, ainda que indiretamente, para a consecução do empreendimento imobiliário em questão, o que basta para que seja titular em tese da relação jurídica afirmada em juízo. Em outras palavras, restou evidenciado nos autos que todas as rés uniram esforços no sentido de viabilizar o empreendimento imobiliário em questão. Tal comportamento concludente não é irrelevante em termos jurídicos. (TJSP, $1^{\mathrm{a}} \mathrm{Cam}$. De Direito Privado, Des. Francisco Loureiro, Apelação n ${ }^{\circ}$ 1001390-67.2016.8.26.0344, j. 17/01/2017, D. registro 17/01/2017)
} 
concludente como elemento do negócio jurídico, ainda que seja considerado como declaração tácita ${ }^{10}$. No nosso sentir, trata-se de questão superada. A problemática do comportamento concludente encontra-se na forma interpretativa das circunstâncias e das provas necessárias a sua caracterização. Isso só poderá ser esclarecido no caso concreto, demandando do aplicador do direito estudo e análise do conjunto fáticoprobatório.

\subsubsection{Contrato sem negócio jurídico ou negócio de fato}

A discussão sobre a existência de negócios de fato na Alemanha iniciou-se a partir do caso julgado pelo Tribunal Federal (Bundesgerichtshof - BGH) referente a estacionamento formado a partir da concessão de terreno público, para a administração e cobrança de serviços de guarda e depósito por particular. $\mathrm{Na}$ ocasião a prefeitura de Hamburgo assim procedeu dada a escassez de áreas de parque para estacionamento no cento da cidade e uma usuária recusou-se ao pagamento após utilizar dos serviços ${ }^{11}$. À época, Günter Haupt ${ }^{12}$ formulou a ideia de "relações contratuais fáticas" cujo vínculo derivava não de um acordo negocial válido (como encontro de vontades), mas de relações jurídicas de direito contratual estabelecidas a partir de uma fattispecie social vinculante para os envolvidos, relações essas que se originam da própria praxe social (LARENZ, [1956] 2006, p. 57). Desenvolvendo e aperfeiçoando a ideia presente no conceito proposto por Haupt, Karl Larenz, constrói seu entendimento a partir da moderna ideia de circulação de bens representada pelos contratos de massa, principalmente o contrato de transporte público, em que a declaração ao público é feita pela divulgação de tarifas , de sorte que qualquer um pode fazer uso de fato da prestação, sem prévia conclusão contratual - ou seja, por meio de acordo expresso ou tácito de vontades - sobre a prestação e preço. Como não há negociação entre o cobrador e o passageiro, mas a utilização real do transporte, conclui-se que o contrato em questão tem por base os usos e costumes do comércio. É o que autor define como aceitação fática de uma prestação oferecida faticamente (LARENZ, [1956] 2006, p. 58). O efeito obrigatório do comportamento do usuário não está na expressão de sua vontade própria em obrigar-se, mas sim no seu comportamento (comportamento social típico), compreendido dentro dos usos e costumes do tráfego. Como assinala é a 'resposta' ou 'reação' social típica à oferta e tem, por isso, o significado socialmente típico de uma fonte de obrigação. Essa relação obrigacional gera um comportamento social típico relevante

\footnotetext{
10 O que no nosso sentir não é o caso. O comportamento concludente, tal como a declaração de vontade, é apto como elemento essencial à formação do contrato, pois também é reconhecido como ato social relevante, portanto, merecedores da devida tutela jurídica, na linha do que foi exposto por Emílio Betti na Itália.

$11 \quad$ Decisão da 5 a Câmara de Direito Civil de 14.07.1956 (NJW 56, 1475).

12 Segundo tal concepção, existiam na sociedade relações contratuais fáticas com três grupos definidos: a) aqueles decorrentes de "contatos sociais", incluindo aqui os deveres pré-contratuais; b) os decorrentes de "coletividades fáticas" ( como contratos de trabalho e sociedade); e c) os estabelecidos por "relações contratuais fáticas em virtude de uma obrigação de prestar social (contrato de transporte). (LARENZ, [1956] 2006, p. 59).
} 
juridicamente e válido, desde que não infrinja proibição expressa legal ou os bons costumes (limites gerais no $\S \S 134$ e 138 BGB) (LARENZ, [1956] 2006, p. 60/61). Não podemos asseverar que essa teoria seja amplamente aceita no Brasil. Entre nós, a aceitação de teorias que tendem a um entendimento extensivo do negócio jurídico é o viés pelo qual a doutrina e os tribunais têm-se direcionado, como indicado no item anterior. Ou seja, entre nós a tendência seria a de admitir-se que os atos no seio de atividades e o comportamento concludente representariam modos específicos de manifestar a vontade, de modo que poderiam ser conjugados em uma compreensão mais extensa de negócio jurídico.

Contudo, podemos encontrar ao menos um representante da teoria restritiva do negócio jurídico, que admite a existência de contratos sem negócio. A obra de Juliana Pedreira Silva propõe uma releitura do conceito de contrato, a partir dessa segunda corrente. O fato de haver o reconhecimento de contratos a partir de atos ou comportamentos coordenados a partir de centros de interesse, sem a presença necessária da declaração de vontade, leva a autora ao entendimento de que

o contrato, como baluarte das relações jurídicas patrimoniais, deve ser entendido como atividade, isto é, como uma coordenação objetiva de atos ou comportamentos deflagrados por centros de interesse. $O$ contrato, compreendido como atividade, impede que se imponha a vontade como condição de coordenação dos atos e, portanto, é possivel identificá-lo sem invocar a fórmula do negócio jurídico (SILVA, 2011, p. 15).

\subsection{A relatividade da forma solene}

O formalismo presente no Direito Romano do período arcaico foi gradativamente sendo substituído pela consensualidade ${ }^{13}$, que, por fim, conduziu a liberdade de forma das convenções (BESSONE, 1997, p.108/109). Por isso mesmo, no nosso ordenamento jurídico a validade das declarações de vontade não depende de uma forma especial, em regra, salvo quando a lei expressamente assim exigir (art.107 do CC), sendo a exigência de uma forma determinada, portanto, um resquício que alcança apenas os contratos denominados solenes. Vale ressalvar que, inicialmente, o contrato necessita ter uma forma (que não se confunde com formalidades ou solenidades), ainda que não determinada em lei. Sem forma, o contrato não existe (AZEVEDO, 2010, p. 126). Esse é elemento essencial, como já salientando no item anterior. Dessarte,

\footnotetext{
13 O nexum e a stipulatio são exemplos de atos solenes do período arcaico, que se estende, aproximadamente, até o século II a.C. No período clássico, o Direito Romano tende à informalidade, aceitando-se a formação de contratos solo consensu, como a compra e venda, a locação, a sociedade e o mandato. Tais figuras convivem com as formas antigas, que por seu lado dão lugar a negócios abstratos. Esclarece José Carlos Moreira Alves: “Já no tempo de Gaio, ao lado das obligationes re, uerbis e litteris (isto é, obrigações nascidas de contratos que seguiam esse esquema), há quatro contratos consensuais em que a obrigação nasce apenas do consensus (consentimento, acordo de vontade): obligationes consensu (obrigações decorrentes do acordo de vontade)." (ALVES, 2014, p. 472).
} 
estamos tratando do campo na validade. Essa é a posição doutrinária contemporânea, como assinala Renan Lotufo: Clóvis dizia, em relação ao texto anterior: "tal exigência, sendo da substância do ato, equivale a dizer que sem isso, não poderá existir" (Código Civil dos Estados Unidos do Brasil comentado, p. 424), o que não corresponde exatamente à colocação doutrinária contemporânea, que não vê inexistência, mas falta de validade. Sem a forma imposta pela lei o negócio não produz os efeitos desejados, já que não poderá ser o documento produzido particularmente objeto do devido registro (LOTUFO, 2004, p. 283).

Com isso, quer-se dizer que uma forma, qualquer que seja, é necessária para a existência do contrato. A qualificação da forma pela licitude é que o influencia, quando solene, no plano da validade. Assim, quando nos referimos à "forma", o contrato já existe e estamos diante do exame da qualidade dessa forma seja ela livremente adotada pelas partes (podendo ser expressa ou tácita; ativa ou omissiva; inclusive a partir do silêncio qualificado) (AZEVEDO, 2010, p. 127/130); ou porque a forma obedece às formalidades ou solenidades requisitadas pelo legislador; ou ainda porque a forma existe ainda que em desacordo com as exigências do legislador. É sobre esse último aspecto que trataremos. Sempre que a norma prescrever um determinado formato, esse será requisito da validade do contrato. E o contrato necessita ser válido para que sejam assegurados os efeitos pretendidos pelas partes (eficácia), afastada sua nulidade. Essa é a linha eleita classicamente pela doutrina.

No nosso sistema o contrato solene (alguns doutrinadores preferem o termo formal) ${ }^{14}$ deve seguir forma pré-determinada ou prescrita em lei para sua validade. Assim, o artigo 108 do CC/2002 prescreve que a escritura pública é essencial aos negócios jurídicos que visem à constituição, transferência, modificação ou renúncia de direitos reais sobre imóveis de valor superior a trinta vezes o maior salário mínimo vigente no País. O mesmo ocorre para os casos de testamento público (art. 1864 do CC) e pacto antenupcial (art. 1653 do $\mathrm{CC}$ ). Em outros casos, a lei exige o escrito particular, pelo menos, como no mandato ad judicia, na doação (em regra: art. 541 do CC) e na fiança (art. 819 do CC). Uma forma pré-determinada também pode ser eleita pelos próprios contratantes que a estabelecem no negócio jurídico. Por exemplo, cláusula de não valer o acordo sem instrumento público (art. 109 do CC/2002) ${ }^{15}$. Assim, a partir dos exemplos dados, podemos

\footnotetext{
14 Os autores discutem quanto à nomenclatura formal e solene. Para autores como José de Abreu não seria suficiente falar apenas em solene e não solene, já que seu entendimento passa pela ideia de que existem contratos cuja forma escrita seria obrigatória, mas sem a presença de uma autoridade (como na hipótese translativa de direito reais sobre imóveis de pequeno valor) o que seria formal, mas não solene (ABREU FILHO, 1995 ,p. 98/99). Desse entendimento discorda Marcos Bernardes de Mello, que compreende não ser pertinente o negócio não formal, afinal todos, como mencionamos antes, têm forma, apenas, umas são solenes e outras simples. (MELLO, 1995, p. 186).

15 Assim: No direito hodierno, no tocante aos negócios jurídicos, vigota princípio da liberdade de forma em razão do qual a exigência de forma solene constitui exceção. Apesar disso, em alguns casos, a forma assume tal importância que é incluida, até, entre os elementos constantes do núcleo do suporte fáctico, como ocorre no casamento e no testamento. Nesses casos, que são os mais excepcionais, a inobservância da forma importa a própria inexistência do negócio jurídico, como
} 
encontrar duas espécies de contratos solenes. Os contratos solenes ad probationem tantum, cuja forma é exigida para fins de prova, mas a mesma pode ser suprida por outros meios probatórios (PEREIRA, 2009, p. p.30) ou, então, sua validade é mantida, mas com limitações quanto à extensão da eficácia em relação a terceiros ${ }^{16}$; e os contratos solenes ad substantiam, cuja forma mínima integra a própria substância e constituição do ato, exigida pela lei como requisito essencial à validade do contrato, o que acarretaria em sua nulidade, se não observada. Com a vigência do Código de Processo Civil de 2015, a forma ad probationem de origem legal foi abandonada para os contratos de valor superior a 10 salários mínimos. A codificação anterior proibia a prova exclusivamente testemunhal acima desse limite (CPC de 1973, art. 401), mas essa regra era de prova e não relativa à substância do ato. Hoje, a forma ad probationem é mais um problema de conveniência das partes, no que diz respeito ao valor dos contratos.

Situação em que a forma contratual ganha importância como prova ocorre, por exemplo, na lavratura do assento de casamento no livro de registro (art. 1.536 do $\mathrm{CC} / 2002$ ), já que não é essencial à validade do ato.

Alguns autores classificam como contrato solene (ad solemnitatem ou ad substantiam) o contrato de seguro, pelo fato de requerer forma escrita, sendo considerado um contrato perfeito a partir na emissão da apólice, uma vez preenchida a proposta com a declaração dos elementos essenciais do interesse a ser garantido e do risco ${ }^{17}$. Entretanto, os termos do artigo 758 do CC tratam da exibição de apólice ou do bilhete de seguro como prova do seguro, podendo ser apresentados outros documentos na falta dos primeiros, razão pela qual, em no nosso sentir, também se trata de um exemplo da espécie ad probationem tantum. Esse entendimento também é consagrado por Carvalho Santos que, na vigência do Código Civil de 1916, entendia suficiente a comprovação do pagamento para provar a existência do contrato. ${ }^{18}$ Aliás, podemos encontrar

mostramos no $\S 12,5$. De ordinário, porém, a forma solene constitui elemento complementar do suporte fáctico, implicando, assim, questões de validade. Os contratos constitutivos ou translativos de direitos reais sobre imóveis acima de um certo valor, os pactos antenupciais, as adoções são exemplos de negócios jurídicos solenes em que a forma não lhes é essencial à existência, mas à validade. (MELLO, 1995, p.186).

16 É o que Antonio Junqueira de Azevedo trata como fatores de atribuição de eficácia mais extensa, que são os indispensáveis para que um negócio, que já possui plena eficácia, inclusive produzindo os efeitos esperados, possa surtir efeitos oponíveis a terceiros ou, até mesmo, erga omnes. (AZEVEDO, 2010, p. 57)

$17 \quad$ Nesse sentido aponta Maria Helena Diniz: O contrato de seguro é formal, visto ser obrigatória a forma escrita, já que não obriga antes de reduzido a escrito (RT, 167:364, 511:130, 526:212 e 493:73), considerando-se perfeito o contrato desde o momento em que o segurador remete a apólice ao segurado, ou faz nos livros o lançamento usual da operação (EJSTJ, 4:71) (...) A forma escrita é exigida para a substância do contrato, embora alguns autores entendam que é reclamada apenas 'ad probationem' não havendo forma escrita especifica, sendo, por isso, consensual. (DINIZ, 2008, p. 533)

Mesmo que não haja a expedição da apólice, se a Companhia recebeu o pagamento do primeiro prêmio, ai está a prova de houve proposta de aceitação, tendo o segurado tido ciência das condições das apólices e com elas se conformado, podendo mesmo dizer-se com Espínola que o mútuo consentimento das partes manifestou-se em relação às cláusulas usuais da apólice a ser expedida. (SANTOS, 1958, p. 214) 
decisões que vão além nesse entendimento, considerando a simples proposta de seguro enviada à seguradora, assinada por representante da seguradora (uma vez que contenha os dados essenciais para a oferta) e pagamento do prêmio como provas suficientes, inclusive, para se constituir em título executivo extrajudicial ${ }^{19}$. Exemplo análogo é o do transporte de coisas. A lei exige a emissão de conhecimento (art. 744 do CC). Mas a ausência dessa forma não invalida o contrato de transporte, pois se trata de mero título de legitimação, servindo outrossim de prova do negócio.

Assim, nos contratos impropriamente solenes, como os que acabamos de discutir, uma vez não observada a exata forma exigida em lei, não há nulidade do negócio. O que pode ocorrer no caso concreto é uma dificuldade de prova, principalmente se há questões de ordem judicial; contudo, a questão poderá ser sanada por outros meios probatórios. É o que se observa da ementa do Tribunal de Justiça do Estado de São Paulo, da 4ª Câmara de Direito Privado, Apelação n ${ }^{\circ}$ 0138174-42.2007.8.26.0002, tendo como relator o Des. Ênio Zuliani, decisão julgada em 13/02/2014, nos autos da adjudicação compulsória:

Adjudicação compulsória (art. 466-B, do CPC). Viabilidade de emitir sentença que consolide o domínio mediante exibição de recibo dotado dos requisitos essenciais do negócio preliminar e com expressão própria da sua irreversibilidade. Decurso de mais de 40 anos e que demonstra exercício de direitos decorrentes do contrato informal. Provimento para julgar procedente a ação.

Essa é a mesma linha encontrada na obra de Arnoldo Wald que, referindo-se aos casos de compra e venda de imóvel por instrumento particular, embora assevere a impossibilidade de transferência de propriedade, afirma ser o instrumento suficiente para ensejar a ação judicial com o intuito de obter registro. Assim o contrato solene, quando realizado sem a forma estabelecida por lei, poderá valer com outra finalidade, mas não atenderá à sua função precípua (WALD. 2001, p. 224). Hipótese em que há limitação da extensão da eficácia, mas não nulidade, é o caso da cessão de crédito realizada por instrumento particular, não levada a registrado público. Isso não será impeditivo da cobrança da dívida pelo cessionário, diante do descumprimento do devedor, mas o instrumento só vale entre as partes (e devedor devidamente notificado), não sendo extensível a terceiros.

Quanto aos contratos cuja solenidade é caracterizada ad substantiam, a regra é a decretação da nulidade diante da ausência de solenidade especial ao ato (art. 166 VI e V do CC/2002). Como assinala Caio

\footnotetext{
19 Conferir neste sentido o seguinte julgado: SEGURO. Execução. Proposta. A proposta de contrato de seguro de acidentes pessoais assinada pelo representante da seguradora, a que se soma o recebimento dos prêmios, é título executivo. Execução promovida pela beneficiária. Recurso especial conhecido e provido, para julgar improcedentes os embargos da seguradora. (STJ, REsp 259798/BA, Quarta Turma, Rel. Min. Ruy Rosado de Aguiar, Dj 19/10/2000, DJ 18/12/2000 p. 205)
} 
Mário da Silva Pereira, na formalidade instituída ad solemnitatem a validade da declaração está em jogo. Se não se revestir daquela forma determinada, o ato não subsiste (PEREIRA, 2009, p. 54). É o que se observa nas decisões quando se trata de doação (Art. 541 e 108 do CC/2002) (20 $^{20}$ testamento (arts. 1864, 1868, 1876 do CC/2002) e cessão de direitos hereditários (arts. 1793 e 1974 do CC/2002) ${ }^{21}$ em que o entendimento dos tribunais tem seguido à risca as exigências especiais da forma, que, por vezes, pode se referir ao número de testemunhas, forma escrita e registro público ${ }^{22}$. Quando há exigência de escritura pública, tem-se admitido a possibilidade de o ato também ser reduzido a termo nos próprios autos do inventário ou partilha, em substituição ao registro público ${ }^{23}$. Não obstante, em alguns casos, ainda que formalidade do contrato impacte

20 Assim: APELAÇÃO CÍVEL. PROMESSA DE COMPRA E VENDA. AÇÃO REVOCATÓRIA. DOAÇÃO. INEXISTENCIA. SENTENÇA DE IMPROCEDÊNCIA MANTIDA. Inexistindo ato formal de doação, que é negócio solene segundo artigo 541 do Código Civil, não há como reconhecer a pretensão revocatória. Sentença de improcedência mantida. Apelo desprovido. Unânime (Apelação Cível No 70070105861, Décima Sétima Câmara Cível, Tribunal de Justiça do RS, Relator: Liege Puricelli Pires, Julgado em 27/10/2016) e Apelação - Pedido de manutenção na posse de imóvel Improcedencia - Impossibilidade de reconhecimento de "doação verbal" do bem - Ato solene, para o qual exige a lei formalidade especifica - Comodato não desconstituído - Circunstância comum, observada entre parentes (pai e filho) Comprovação de pagamentos de contas de consumo ou tributos que não se mostra suficiente para, por si só, afastar a alegação de comodato, uma vez admitida a modalidade do "comodato com encargo" (ou modal) -Existência de notificação, configurando o esbulho - Alegação da usucapião prejudicada pela ausência de comprovante da posse justa - Arguição que se restringe à matéria de defesa - Domínio que deve ser buscado em ação própria - Pedido de indenização ou retenção que é apresentado de forma genérica, não podendo ser acolhido nesta via - Decisão mantida - Recurso improvido. (TJSP, Apelação no 1012158-90.2014.8.26.0451, 24 Câmara de Direito Privado, Des. Claudia Grieco Tabosa Pessoa, j. 25/02/2016) 21 Neste diapasão: Sucessões. Publicação, registro e cumprimento de testamento particular. Sentença de improcedência. Irresignação. Desacolhimento. Ato jurídico solene e formal. Cédula que não foi lida nem assinada pelo testador na presença das testemunhas. Inobservância de formalidade legal (art. 1.876, $\S 2^{\circ}$, do Cód. Civil). Impossibilidade de comprovação da manifestação de vontade do de cujus, nos termos do art. 1.878 do Código Civil. Predomínio da vontade sobre a disposição legal. Impossibilidade. Reclamo da meeira quanto à observância da forma que faz preponderar a sucessão legítima sobre a testamentária. Sentença mantida. Recurso desprovido. (TJSP, Apel. $\mathrm{n}^{\mathrm{o}}$ 0001632-20.2015.8.26.0363, $7^{\mathrm{a}}$ Câmara de Direito Privado, Des. Rômolo Russo, j. 18/04/2016 e DIREITO CIVIL. SUCESSÕES. ARROLAMENTO DE BENS. CESSÃO DE DIREITOS HEREDITÁRIOS. EXIGENNCIA DE INSTRUMENTO PÚBLICO. POSSIBILIDADE DA REALIZAÇÃO POR TERMO NOS AUTOS DESDE QUE PERFECTIBILIZADA PESSOALMENTE PELOS RENUNCIANTES OU POR PROCURADOR COM PODERES ESPECIAIS OUTORGADOS POR INSTRUMENTO PÚBLICO. AGRAVO DE INSTRUMENTO PROVIDO. A cessão de direitos hereditários, para ter validade e eficácia, há que ser formalizada, ou por escritura pública, ou por termo nos próprios autos de inventário ou arrolamento, impondo-se, na última hipótese, seja o termo assinado pessoalmente pelo herdeiro cedente ou por procurador munido de poderes especiais para realizar a cessão, poderes esses conferidos por instrumento público de mandato. É a exegese que resulta da interpretação sistêmica dos arts. 1.793 e 1.806 do atual Código Civil. (TJSC, Segunda Câmara de Direito Civil, Processo no 2012.069305-3, Rel. Trindade dos Santos, j. 21/03/2013)

22 Mas não são os únicos. Na visão de Viviane Perez: Pode-se concluir que o fundamento da adoção de determinada forma especial residiria na necessidade de conferir mais segurança a determinados atos e contratos jurídicos que, por sua relevância , demandariam maior reflexão das partes para sua celebração e certeza mais precisa sobre o conteúdo declarado da vontade. Mas quais são os atos e negócios jurídicos que exigem forma especial?Como regra, todos os que envolvam imóveis com valor superior a trinta salários-mínimos (art. 541 do NCC), o mandato (arts. 653 a 655 do NCC), a constituição de renda (art. 808 do NCC), a fiança (art. 819 do NCC), os direitos reais de garantia (art. 1.424 do NCC), o casamento (art. 1.533 e ss. do NCC), o reconhecimento de filhos (art. 1.609 do NCC), o testamento (arts. 1.864, 1.868, e 1.878 do NCC) os títulos de crédito em geral. (PEREZ, 2007, 181)

23 Agravo de Instrumento - inventário - Renúncia de meação e instituição de usufruto vitalício em favor da viúva Possibilidade - Partilha amigável - Formalização por meio de escritura publica - insurgência - Ato translativo que pode ser tomado por termo nos autos - Inteligência do art. 1.806 do Código Civil-concordância de todos os herdeiros - ausência de 
na substância dos contratos, observa-se uma mudança de postura do legislador, visando a considerar as atitudes dos contratantes que agiram de boa fé, relativizando os efeitos da aplicação de normas que possam estar dissociadas dos valores emanados da sociedade e reconhecidos pela ordem jurídica, ainda que sejam hipóteses legais excepcionais.

Isso implica na consideração da função do contrato, da intenção das partes e do aproveitamento possível dos atos, todos aliados a estrutura contratual para a produção de efeitos, segundo cada caso concreto, ainda que esses efeitos possam ser limitados ou não correspondam exatamente aos que decorreriam de ato perfeitamente constituído. Aliás, por esses mesmos critérios, pode-se considerar, até mesmo, uma revisão para obstar a produção de efeitos, ainda que a forma solene tenha sido aparentemente observada.

Neste último caso, temos, verbi gratia, decisão do Tribunal de Justiça de São Paulo em ação anulatória de pacto antenupcial com comunhão universal de bens, em que se espera uma mínima vida conjugal em comum, a fim de justificar a comunicação dos bens de cada consorte e aqueles adquiridos na constância da união. Na hipótese, o pacto seguiu-se de casamento, condição para sua eficácia, mas quase não houve convivência entre os cônjuges. Desse modo, se não houve sequer tempo para uma real convivência, diante do litígio imediato, não é possível garantir os efeitos pretendidos do pacto, pois sua aplicação implicaria em violação da boa fé, exigida, inclusive, dos consortes. ${ }^{24}$ Ao aviso do jurista italiano Pietro Perlingieri, não se deve buscar somente a estrutura (forma) do negócio jurídico ou contrato. A função e sua interpretação em uma perspectiva axiológica-constitucional são aspectos essenciais. Em suas palavras:

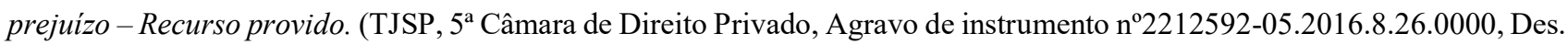
Moreira Viegas, j. 14/12/2016) e Agravo de Instrumento. Arrolamento - Decisão que determinou a comprovação de protocolo de procedimento administrativo de ITCMD e a renúncia da herança pelos herdeiros em favor da viúva inventariante por meio de escritura pública de doação - Renúncia da herança em favor de pessoa determinada que é possível de realização por termo nos autos de inventário, desde que recolhido o ITCMD devido a título de doação - Questão acerca do ITCMD devido pela sucessão "causa mortis" que deve ser resolvida na esfera administrativa - Inteligência do parágrafo $2^{\circ}$ do artigo 659 do Novo Código de Processo Civil - Suficiente a intimação da Fazenda do Estado para lançamento do tributo após o trânsito em julgado da sentença de homologação da partilha ou adjudicação. Dá-se provimento em parte ao recurso. (TJSP, Agravo de instrumento $n^{\mathrm{o}}$ 2146050-05.2016.8.26.0000, $1^{\text {a }}$ Câmara de Direito Privado, Des. Christine Santini, j. 10/10/2016) ${ }_{24}$ É o que se extrai da seguinte ementa: Ação anulatória - Tutela antecipada que suspendeu os efeitos do pacto antenupcial firmado entre as partes - Manutenção - Como qualquer negócio jurídico, está sujeito a requisitos de validade e deve ser iluminado e controlado pelos princípios da boa-fé objetiva e da função social - Não se alega coação e nem vício de consentimento, mas nulidade por violação a princípios cogentes que regem os contratos - Pressupõe o regime da comunhão universal de bens a comunhão de vidas, a justificar a construção de patrimônio comum, afora as exceções legais - O litígio entre o casal, que desbordou para os autos do inventário da genitora da autora, e a significativa mutação patrimonial fundada em casamento de curtíssima duração, autorizam a suspensão dos efeitos do pacto antenupcial - Não há como nesta sede acatar os argumentos do recorrente acerca de violação a direito adquirido, ou a exercício regular de direito, pois o que por ora se discute é a validade do negócio nupcial, e sua aptidão a gerar efeitos patrimoniais - Decisão mantida - Recurso não provido. (TJ/SP, 4a Câmara de Direito Privado, Agravo de instrumento em ação anulatória n 0126301-17.2008.8.26.0000, Des. Francisco Loureiro, j. 10/07/2008)
} 
A forma pode ser relacionada a um ou mais perfis, cumulativamente ou alternativamente, segundo a 'ratio' da norma que a estabelece. Individuar esse fundamento é indispensável para proceder a uma interpretação que não seja separada de sua valoração. Isso, inelutavelmente, significa que toda forma negocial tem necessariamente uma função, ainda que heterogênea. Nem se pode alegar em contrário que o art. $1325, n^{\circ} 4$, indica a forma dos atos substanciais 'como simples elemento de estrutura'. A estrutura como 'totalidade recolhida em si' não seria legitimada pelos fins externos. Todo 'como' do direito tem sempre um 'porquê' juridicamente relevante: o art. $1325, n^{\circ} 4$, é somente uma fragmentação de norma que se integra a cada vez com a disciplina de cada ato. O porquê (a função) extraí-se não da previsão da 'sanção' nulidade, mas do necessário fundamento da previsão normativa (PERLINGIERI, 2007, p. 295/6).

Quanto à ideia excepcional de relativização da forma, nos contratos solenes na modalidade $a d$ substantiam, destacam-se as situações que envolvem: o princípio da boa fé objetiva (arts. 113 e 422 do CC 2002); o aproveitamento dos atos a fim de ressalvar os direitos de terceiros de boa-fé (arts. $167, \S 2^{\circ}$; 221; $288 ; 359,522,563,926,1563$ e ss do CC/2002) e a conversão do negócio jurídico nulo (art. 170 do CC).

\subsubsection{Princípio da boa fé objetiva}

A boa-fé é o princípio geral a que todas as obrigações devem se subordinar (art. 113, 187 e 422 CC/2002). Associa-se a uma das características da liberdade contratual que é a autovinculação, mandamento moral de preservar a confiança dada e assumida numa relação obrigacional livremente pactuada (LARENZ, 2001, p. 90). Aplica-se em todo o processo obrigacional Incide desde os primeiros contatos negociais entre as partes, acompanha o desenvolvimento do contrato até superar o seu fim determinando deveres secundários pós-contratuais, segundo a natureza e complexidade do vínculo contratual ${ }^{25}$. Tomada a obrigação contratual, desta feita, na forma de um processo dinâmico, que comporta diferentes fases, a boa-fé estará presente em todas elas, determinando que as partes sejam probas, leais, cooperativas, atuando com ética e fazendo o necessário para facilitar ou não obstar que as mesmas alcancem seus interesses, externados no contrato.

E, evidentemente, nesse processo é possível que a força do princípio da boa-fé objetiva possa ter resultar na modificação ou adaptação da eficácia do contrato. É nesse sentido que Joaquim Ribeiro de Souza assevera que a boa fé pode intervir como uma norma de validade (SOUZA, 2007, p. 229). ${ }^{26}$ Entre as funções:

\footnotetext{
25 Apesar do artigo 422 não se referir expressamente a todas estas fases, é extreme de dúvidas que a boa-fé não encontra limites nesta linha. É o que se extrai do enunciado n. 170 da III Jornada de Direito Civil do CJF (Conselho de Justiça Federal): "Art. 422: A boa-fé objetiva deve ser observada pelas partes na fase de negociações preliminares e após a execução do contrato, quando tal exigência decorrer da natureza do contrato".

$26 \quad \mathrm{O}$ aspecto por ele tratado se vincula a ideia de controle de conteúdo que tem por objetivo a validação ou não da preceptividade jurídica que a cláusula contratual reinvindica, portanto uma função de limite ao direito subjetivo. Mas ainda
} 
$1^{\text {a) }}$ hermenêutica-integrativa; $2^{\mathrm{a}}$ ) de criação de deveres secundários e $3^{\mathrm{a}}$ ) função limitadora do exercício de deveres secundários, ressaltamos como mais significativas em matéria de solenidade contratual a primeira e a última modalidade. A boa-fé é um princípio que pode ser aplicado em conjunto com outros, como o princípio da conservação do negócio jurídico, como aponta Alexandre Dartanhan de Mello Guerra ao concluir que nos negócios solenes, a superação das deficiências formais deve ser prestigiada se assim for necessário para salvaguardar o fundamento axiológico-constitucional albergado pela ordem pública (GUERRA, 2012, p. 516). Nessa perspectiva, ainda na vigência do Código Civil anterior, o Superior Tribunal de Justiça, Terceira Turma, tendo como Ministro relator Waldemar Zveiter em decisão datada de 03.03.1998, envolvendo a validade da tradição simbólica de bem dado em penhor mercantil, destacou que mera aceitação do encargo pelo depositário, no penhor mercantil, faz presumir a tradição dos bens dados em garantia, (...). sendo certo que a realidade das relações de comércio dos tempos atuais repudia os formalismos injustificáveis, instalando-se na boa fé a 'consagração do dever moral de não enganar a outrem. "27 Nessa linha interpretativa, exatamente em hipótese de ato solene ad substantiam, a Quarta Turma do Superior Tribunal de Justiça, no Agravo Regimental no Recurso Especial 1073860/PR, tendo como relator Antônio Carlos Ferreira, julgado em 21.03.2013, ponderada que a análise da regularidade da disposição de última vontade (testamento particular ou público) deve considerar a máxima preservação do intuito do testador, sendo certo que a constatação de vício formal, por si só, não deve ensejar a invalidação do ato, máxime se demonstrada a capacidade mental do testador, por ocasião do ato, para livremente dispor de seus bens. Precedentes do STJ. ${ }^{28}$

\subsubsection{Conversão do negócio jurídico nulo}

A conversão do negócio jurídico nulo é inserida no direito positivo a partir do Código Civil de 2002 (art. 170 do CC/2002) e reflete o princípio da conservação do negócio jurídico, que visa manter a atividade negocial a fim de que a mesma alcance sua finalidade, consoante esperado pelas partes (LOTUFO, 2004, p. 471).

O tema em questão não era desconhecido dos doutrinadores na vigência do Código anterior. Neste sentido, destaca-se a obra de João Alberto Del Nero que tratava essa possibilidade com a finalidade de

podemos apontar as funções interpretativa-integrativa e a função de criação de deveres secundários. É em especial na função interpretativa que poderemos visualizar a relativização da forma solene.

27 Cf. www.stj.jus.br, acesso em 24.01.2017, disponível em DJ 04/05/1998 p. 155; RDR vol. 11 p. 327 ; RT V 00755 p. 223; RT vol. 755 p. 223.

28 Disponível em www.stj.jus.br, acesso em 24.01.2017. 
atribuição ou reconhecimento de (alguma) eficácia ao negócio jurídico prima facie ineficaz lato sensu (DEL NERO, 2001, p. 345/6).

A conversão, como preceitua Emilio Betti, considera os valores no mundo do direito, os quais influenciam modificações nas avaliações jurídicas. Não se trata de transformar o intento prático perseguido - que, aliás, deve ser conservado por aquilo que é -, mas de mudar o meio jurídico de realizá-lo, escolhendo o mais idôneo e agindo sobre a relativa fungibilidade dos meios (BETTI, 2007, p. 315).

Desse modo, a conversão do negócio jurídico é o meio jurídico pelo qual um negócio inicialmente nulo poderá ser considerado válido, com o intuito de salvaguardar sua eficácia jurídico-social na maior extensão possível. Isso leva o intérprete a buscar o resultado prático que as partes pretendiam com a celebração do contrato, sendo manifestação dos princípios da operabilidade e sociabilidade (GUERRA, 2012, p. 471).

A respeito da matéria de Pontes de Miranda ressalta: o fundamento da conversão está em que, nas relações da vida, mais se há de atender aos propósitos de cada um, econômicos ou não, do que à coincidência entre tudo que se quis e a regra jurídica em que se pensou, querendo-se determinada categoria jurídica. Mais à vida que à rigidez das normas que em que se atentara, explícita, ou apenas implicitamente, pela pré-escolha do negócio jurídico (PONTES DE MIRANDA, 2001, p. 104).

Observa-se que nossa doutrina apresenta influência portuguesa no que tange aos requisitos. Assim, para que o negócio jurídico ou contrato inválido possa ser convertido, produzindo os efeitos pretendidos, faz-se necessário que contrato preencha determinados requisitos objetivos e subjetivos, no entendimento de parte considerável da doutrina brasileira ${ }^{29}$.

Para Francisco Amaral os elementos subjetivos incluem a adequação do negócio substitutivo à "vontade hipotética" das partes e como elementos objetivos estão a identidade de conteúdo e forma entre o negócio nulo e o convertido, bem como a identidade do objeto negocial (AMARAL, 2006, p. 534). Renan Lotufo, por seu turno, também aponta como requisito subjetivo a "vontade hipotética" ou conjectural, na ocorrência do resultado prático da conversão, mas também acrescenta a ignorância, pelas partes, do vício que recai sobre o negócio no momento da celebração, denotando sua boa-fé (art. 113 e art. 421 do CC). Como

\footnotetext{
$29 \quad$ No meso sentido entende Vânia Wongtschowski que afirma consideramos, entretanto, que devem ser afastados do instituto da conversão, os elementos subjetivos, que se deve entender que a conversão pode se realizar quando se puder verificar que os efeitos advindos do "negócio sucedâneo" sejam compatíveis com os efeitos que adviriam do negócio primitivo, não fosse sua invalidade ou ineficácia. (WONGTSCHOWSKI. 2008, p. 12).
} 
requisito objetivo indica a existência de um negócio inicialmente nulo, como suporte fático (LOTUFO, 2004, 472).

De outro lado, a vontade hipotética das partes é mais considerada um requisito essencial, de acordo com a concepção preceptiva do negócio jurídico. A declaração de vontade sai da esfera subjetiva de apreciação das partes para uma apreciação que advém do próprio meio social e da forma pela qual se torna merecedora de tutela jurídica.

As modalidades de conversão incluem a judicial (quando a conversão se dá por intervenção do Estado-juiz que, mediante sentença e conforme a provocação das partes, declara a conversão do negócio nulo em seu "sucedâneo") e a legal (hipóteses contempladas pela própria lei. V.g. o artigo 20 da Lei Uniforme de Genebra e o artigo 431 do CC/2002).

A conversão também poderá ser substancial ou formal. A conversão substancial ocorre quando há mudança do tipo contratual ou da natureza do título, por exemplo, um contrato de locação que se torna contrato de comodato ou um título de crédito que padece de vício formal, mas pode funcionar como prova de obrigação entre as partes (AMARAL, 2006, p. 534). Já a conversão formal, por sua vez, não implica na mudança do tipo contratual ou da espécie do título, mas apenas alteração da forma original para que o negócio mantenha a produção dos seus efeitos, ressalvada a falta do elemento formal, que, todavia, não atinge a essência do negócio ou contrato (AZEVEDO, 1974, p. 183/4). ${ }^{30}$

Tanto a conversão substancial quanto a formal podem ocorrer diante da ausência ou incompletude do requisito solene no contrato. A situação será definida no caso concreto.

Como exemplo de conversão substancial do negócio, temos o caso de compra e venda acompanhada de escritura pública convertida em doação ${ }^{31}$. Na ocasião, pessoa capaz, mas debilitada fisicamente, vendeu imóvel. $\mathrm{O}$ vendedor não recebeu efetivamente o preço, nem procurou receber, dado seu espírito de liberalidade justificado pelo auxílio que os compradores lhe prestaram durante a evolução de sua doença até sua morte. Após o falecimento do vendedor, os herdeiros tentaram desconstituir o negócio. Nos termos do trecho do acórdão proferido pela $7^{\text {a }}$ Câmara Cível do Tribunal de Justiça do Paraná, nos autos da apel. no 728088-6, Rel. Des. Guilherme Luiz Gomes, julgado em 17/05/2011:

30 A conversão dos negócios jurídicos: seu interesse teórico e prático. Revista de Faculdade de Direito da USP, vol. 69 , n. 1, 1974, p.183 e184.

31 A conversão substancial de negócio jurídico também se deu em situação em que uma doação de bem fungível, não registrada (portanto, nula) foi convertida em mútuo a titulo gratuito. Veja neste sentido decisão da terceira turma do Superior Tribunal de Justiça, Rel. Min. Nancy Andrighi (REsp 1225861/RS, Terceira Turma, Min. Nancy Andrighi, j. 22/04/2014, Dje 26/05/2014, disponível em www.stj.jus.br. Acesso em 15.01.20117). 
Por outro lado, mesmo verificando-se a nulidade do negócio - posto que os próprios réus admitiram que não houve o pagamento do preço, condição essencial da compra e venda-, ainda assim seria possivel considerar sua conversão, nos termos do artigo 170, do Código Civil, como fundamentado pelo digno Magistrado sentenciante, porquanto a prova dos autos demonstrou que se tratava de doação aos réus por terem se dedicado a cuidar de Rael Vieira dos Santos em suas atividades cotidianas e acompanhando-o muitas vezes a médicos e hospitais. ${ }^{32}$

Como forma de convenção formal, exemplifica Antonio Junqueira de Azevedo, considera-se a hipótese de contrato que inicialmente não exija forma pública (promessa de compra e venda), mas que as partes resolvem celebrar por escritura pública a fim de conferir maior segurança ao negócio, ganhando as características de um contrato solene. Contudo, posteriormente, se verificada que a escritura pública é nula, porque quem a lavrou não tinha fé pública, ainda assim o negócio valerá como se tivesse sido feito por instrumento particular. Vemos que, na conversão formal, há uma alteração da forma documental escolhida (AZEVEDO, 1974, p. 184). ${ }^{33}$

.Nesse caso, o negócio poderá continuar válido, desde que seja considerada como instrumento particular. Assim, seu tipo contratual continua o mesmo, havendo apenas alteração da forma documental escolhida.

\section{Conclusão}

Ao longo do texto, procurou-se enfocar os aspectos formativos do contrato sob dois ângulos principais: a) a possível dissociação dos conceitos de contrato e negócio, pelo menos parcialmente; e b) a eventual superação das lições clássicas acerca da forma substancial. No decurso desse debate, foram repassados vários princípios, como o da boa-fé e institutos relevantes, como o da conversão do negócio jurídico. Também foram trazidos conceitos doutrinários, sendo exemplos o comportamento concludente das partes, as relações contratuais de fato e os atos compreendidos no seio de atividades. A contribuição que se buscou resume-se a mostrar que a sistematização clássica da declaração negocial, do contrato e da forma substancial, se não deve ser de todo abandonada, deve pelo menos ser relativizada nas ocasiões discutidas.

\section{Formative Aspects of Today Contract}

\footnotetext{
32 Disponível em www.tjpr.jus.br, acesso em 25.01.2017

33 Antonio Junqueira de Azevedo. A conversão dos negócios jurídicos: seu interesse teórico e prático. Revista de Faculdade de Direito da USP, vol. 69, n. 1, 1974, p. 184. Disponível em http://www.revistas.usp.br/rfdusp/article/view/66720
} 
ABSTRACT: This article aims at the discussion of formative aspects of the contract involving its conception as a negotiating act and the form as an element of existence and validity requirement, drawing conclusions that deviate from the traditional view. The qualitative method was followed with bibliographic research. The corollary is that the classic systematization of the negotiation statement, the contract and the substantial form, if not completely abandoned, must at least be relativized on the issues discussed.

KEYWORDS: Contract. Consensus. Business act Concluding behavior. Contractual relations in fact. Substantial form. Form ad probationem. Good faith. Social role. Substantial conversion. Formal conversion.

\section{Referências}

ABREU FILHO, José. O negócio jurídico e sua teoria geral. São Paulo: Saraiva, 1995.

ALVES, José Carlos Moreira. Direito Romano. Rio: Forense, 2014.

AMARAL, Francisco. Direito Civil. Introdução. 6a Ed. Rio de Janeiro: Renovar, 2006.

ASCARELLI, Tulio. Corso di diritto commerciale: introduzione e teoria dell'impresa. Milano: Giuffré, 1962. AULETTA, Giuseppe. Attività. In: Enciclopedia del diritto. III. Milano: Giuffré. 1958.

AZEVEDO, Antonio Junqueira de. Negócio Jurídico. Saraiva: São Paulo, 2010. . A conversão dos negócios jurídicos: seu interesse teórico e prático. Revista de Faculdade de Direito da USP, vol. 69, n. 1, 1974, p.183 e184. Disponível em http://www.revistas.usp.br/rfdusp/article/view/66720. Acesso em 28.09.2017.

BESSONE, Darcy, Do contrato:teoria geral. São Paulo: Saraiva, 1997.

BETTI, Emilio. Teoria Geral do Negócio Jurídico. Campinas: Servanda, 2008.

CARVALHO SANTOS. João Manoel. Código Civil Brasileiro interpretado. Rio de Janeiro: Freitas Bastos, vol. XIX, 1958.

CORDEIRO, Antonio Manuel da Rocha e Menezes. Tratado de Direito Civil Português. Parte Geral. T. I. 3. ed. Coimbra: Almedina, 2005.

DEL NERO, João Alberto Schützer. Conversão substancial do negócio jurídico. Rio de Janeiro: Renovar, 2001.

DINIZ, Maria Helena. Código Civil Anotado, São Paulo: Saraiva, 2008.

GOMES, Orlando. Contratos. Rio de Janeiro: Forense.

GUERRA, Alexandre Dartanhan de Mello. Principio da conservação dos negócios jurídicos. Tese de Doutorado, PUC/SP, São Paulo, 2012.

PEREIRA, Caio Mário da Silva. Instituições de direito civil, V. III, Rio de Janeiro: Forense, 2009.

IRTI, Natalino Scambi senza accordo. Rivista Trimestrale di Diritto e Procedura Civile. 1998, vol. 52, 347364. 
LARENZ, Karl. Derecho civil: parte general. Caracas: Edersa, 1978.

LARENZ, Karl. Lehrbuch des Schuldrechts, 14. ed., vol. I München: Beck, 1987. . O Estabelecimento de relações obrigacionais por meio de comportamento social típico (1956), Trad. Alesssandro Hirata. Revista Direito GV, vol. 2, n.1, Jan-jun, 2006, p.55-63. Derecho justo: fundamentos de ética jurídica. Tradução de Luis Díez-Picazo. Madrid: Civitas, 2001.

LOTUFO, Renan. Código Civil Comentado: Parte geral. São Paulo: Saraiva, 2004.

MARTINS-COSTA, Judith. A boa-fé no direito privado: sistema e tópica no processo obrigacional. São Paulo: RT, 1999.

MARTINS-COSTA, Judith. A boa-fé no direito privado: critérios para a sua aplicação, São Paulo: Marcial Pons, 2015.

MELLO. Marcos Bernardes de. Teoria do fato Jurídico. São Paulo: Saraiva, 1995.

MESSINEO, Francesco. Doctrina General del contrato. Tomo I, Europa-America: Buenos Aires.

MIRANDA, Francisco Cavalcanti Pontes de. Tratado de direito privado: parte geral. Tomo V. $2^{\text {a }}$ Ed. Campinas: Bookseller, 2001.

MOTA PINTO, Paulo Cardoso Correia da. Declaração tácita e comportamento concludente no negócio jurídico. Coimbra: Livraria Almedina, 1995.

PEREIRA. Caio Mário da Silva. Instituições de direito civil: contratos, vol. III, Rio de Janeiro: Forense, 2009.

PEREZ, Viviane. Contratos formais e não formais. Abordagem segundo o princípio da boa fé-objetiva. Revista da EMERJ. V.10, n 39, 2007, p.171-188.

PERLINGERI, Pietro. Perfis do Direito Civil: Introdução ao Direito Civil Constitucional. Rio de Janeiro: Reonovar, 2007.

POTHIER, Robert Joseph. Traité des obligations. Tomo I, Paris: Letellier, 1805.

REALE, Miguel. Teoria Tridimensional da norma. São Paulo: Saraiva, 2014.

RIBEIRO. Joaquim de Sousa. Direito dos contratos: estudos. Coimbra: Coimbra, 2007.

SCARELLI. Tulio. Corso di diritto commerciale: introduzione e teoria dell'impresa. Milano: Giuffré, 1962. SILVA. Juliana Pedreira da. Contratos sem negócio jurídico. São Paulo: Atlas, 2011.

SOUZA, Joaquim Ribeiro de. Direito dos contratos: estudos. Coimbra: Coimbra, 2007.

TUTIKIAN. Priscila David Sansone, Silêncio na formação contratual: elementos qualificadores de sua valoração declarativa. Orientadora Judith Martins-Costa, UFRGS, Tese de Mestrado, 2007.

WALD. Arnoldo. Direito das obrigações: teoria geral das obrigações e contratos civis e comerciais. São Paulo: Saraiva, 2001.

WIACKER, Franz. El principio general de la buena fe. 1 ed. Trad. José Luis Carro. Madrid: Civitas, 1986. WINDSCHEID.Bernardo. Diritto delle pandette. Trad. Carlo Fadda e Paolo Emílio Bensa. Torino: UTET, 1902. 
WONGTSCHOWSKI, Vania. Conversão substancial do negócio jurídico. Dissertação de mestrado. PUC/SP, São Paulo, 2008.

Trabalho enviado em 25 de novembro de 2019

Aceito em 06 de fevereiro de 2020 